\title{
Coordinated control of conventional power sources and PHEVs using jaya algorithm optimized PID controller for frequency control of a renewable penetrated power system
}

\author{
Anil Annamraju* (iD and Srikanth Nandiraju
}

\begin{abstract}
In renewable penetrated power systems, frequency instability arises due to the volatile nature of renewable energy sources (RES) and load disturbances. The traditional load frequency control (LFC) strategy from conventional power sources (CPS) alone unable to control the frequency deviations caused by the aforementioned disturbances. Therefore, it is essential to modify the structure of LFC, to handle the disturbances caused by the RES and load. With regards to the above problem, this work proposes a novel coordinated LFC strategy with modified control signal to have Plug-in Hybrid Electric Vehicles (PHEVs) for frequency stability enhancement of the Japanese power system. Where, the coordinated control strategy is based on the PID controller, which is optimally tuned by the recently developed JAYA Algorithm (JA). Numerous simulations are performed with the proposed methodology and, the results have confirmed the effectiveness of a proposed approach over some recent and well-known techniques in literature. Furthermore, simulation results reveal that the proposed coordinated approach significantly minimizing the frequency deviations compared to the JAYA optimized LFC without PHEVs \& with PHEVs but no coordination.
\end{abstract}

Keywords: PHEVs, Optimized PID controller, Coordinated control, Load frequency control, JAYA algorithm

\section{Introduction}

In the present power system scenario, to meet the increasing energy demand from traditional power sources is becoming costly and is also environmentally hazardous, particularly, for islands and remote locations. By accounting these issues, renewable energy sources (RES) would be an attractive alternative solution to fulfill the energy requirements for today's power system. These RES are clean, but are intermittent by nature [1] and this nature of RES brings new operational challenges for grid stability, particularly in frequency control [2].

Minimizing the frequency deviations from the nominal frequency $(50$ or $60 \mathrm{~Hz})$ during the perturbations, and

\footnotetext{
* Correspondence: ani223kumar@gmail.com

Research Scholar, Department of Electrical Engineering, National Institute of Technology Warangal, Warangal, Telangana 506004, India
}

return the frequency to the rated value at steady-state is a primary objective of LFC. The rate of change of frequency describes how near the generation is to the load. In traditional power systems, the frequency instability problem arises only when uncertainty came from the loads [3].

To address this type of LFC problem, several authors proposed different control techniques [4-17]. In [5-7] authors proposed PI/PID controllers based on classical control theory. The classical PID controllers are simple in structure, but the parameters are tuned in trail \& error method. These methods are tuned based on fixed operating conditions. So, to optimize the PID controller parameters according to operating conditions, several authors are proposed various optimization techniques [8-17]. In [8] proposed a GA optimized PID controller, in $[9,10]$ with PSO algorithm, in [11] with teachinglearning based algorithm, in [12] with quasi-oppositional 
harmony search algorithm, in [13] with flower pollination algorithm, in [14] with backstepping algorithm, in [15] with stochastic fractional algorithm, in [16] with differential evolution algorithm, in [17] with artificial bee colony optimization algorithm, in [18] with bat algorithm, etc.

Most of the LFC strategies as mentioned above are tested on traditional power systems and have not accounted the all possible nonlinearities (like generator rate constraint, turbine-reheat mechanism, boiler dynamics, and governor dead-band, etc.) and renewable sources in the system dynamics. The RES penetration into the system/grid causes following technical challenges.

1. In today's modern power system, in addition to the stochastic nature of the load, the intermittent nature of RES output power penetration leads to large frequency fluctuations in the system. The governors of the thermal and hydro units are not adequate enough to minimize the frequency excursions due to their control limitations and the sluggish response [4].

2. Moreover, high penetration of RES (in spite of conventional sources) will also reduce the system inertia with the use of more inverter associated generation units, which makes the system more sensitive to disturbances $[2,4]$.

The above factors challenge the system stability and create large frequency deviations in the system. So, to minimize the frequency deviations to a tolerable limit, the ESSs have turned into an important part in a RES penetrated interconnected power system. In literature, several authors considered various ESSs like BESS, SMES, fuel cells, flywheel energy storage, PHEVs, etc. in the design of a modern power system [19-21]. Among all these ESSs, PHEVs form an excellent option due to their fast-acting capability, distributed availability, and a slow discharge rate while in the idle condition.

Nowadays, because of the RES integration such as solar plant and wind farms in addition to traditional power source non-linearities, the renewable-rich power system faces new technical challenges [2]. The traditional LFC schemes fail to maintain the system frequency within the limit under these conditions [19]. Therefore, these new difficulties prompted the need of novel control strategies in power system operation and control [4]. The amount of RES penetration has been increasing day by day into the non-linear power systems creates large frequency excursions. Therefore, from the LFC perspective, the PHEVs can be utilized as a quick power source in the aim of supporting the frequency control loops for frequency response improvement of the renewable penetrated power system as reported in this work.

In the view of the above investigations, this paper proposes a coordinated control strategy between conventional power sources and PHEVs by introducing PHEVs in LFC, to mitigate the frequency fluctuations in the grid/system. A recently developed Jaya algorithm (JA) has been deployed to obtain the optimal PID controller parameters and to design a robust secondary LFC regulation loop. The reason for selecting this algorithm is, it is an algorithmic specific parameter-free optimization and tuning process is very simple over other techniques in literature. How better the proposed approach in improving the dynamic performance over the other controllers in the literature is presented in results and discussion section.

The contributions and key highlights of the paper are:

1. In this study, a large power system operation and control have been analyzed in the presence of all possible power system nonlinearities and renewable energy sources.

2. A maiden application of JAYA algorithm has been attempted to tune the parameters of the PID controller. The supremacy of the JAYA optimized PID controller in improving the dynamic response of the system is proven by comparing with some recent and standard techniques in literature.

3. A novel coordinated control strategy has been proposed by involving PHEVs with communication delays in the secondary frequency control loop to compensate the LFC during RES penetration.

4. Finally, the proposed controller robustness level has been proven with various critical operating scenarios of the power system.

\section{Modeling of the interconnected power system}

This paper focuses on frequency control of the IEE Japan East 107-bus-30-machine power system including conventional power sources, solar power, wind power, and PHEVs. Figure 1 illustrates a simplified model of the Japanese power system with RES and PHEVs. Figure 2 shows the dynamic model of the Japanese power system considering RES with the proposed coordinated strategy. Each area includes an aggregated model of the thermal and hydro unit with an aggregated speed control and turbine system. In area1, the RES and PHEVs aggregator are included. The detailed modelling of conventional sources with possible nonlinearities are given in Fig. 3. In this study, the dead-band effect of governor is about $0.02 \%$ for a hydro system and $0.04 \%$ for a thermal 


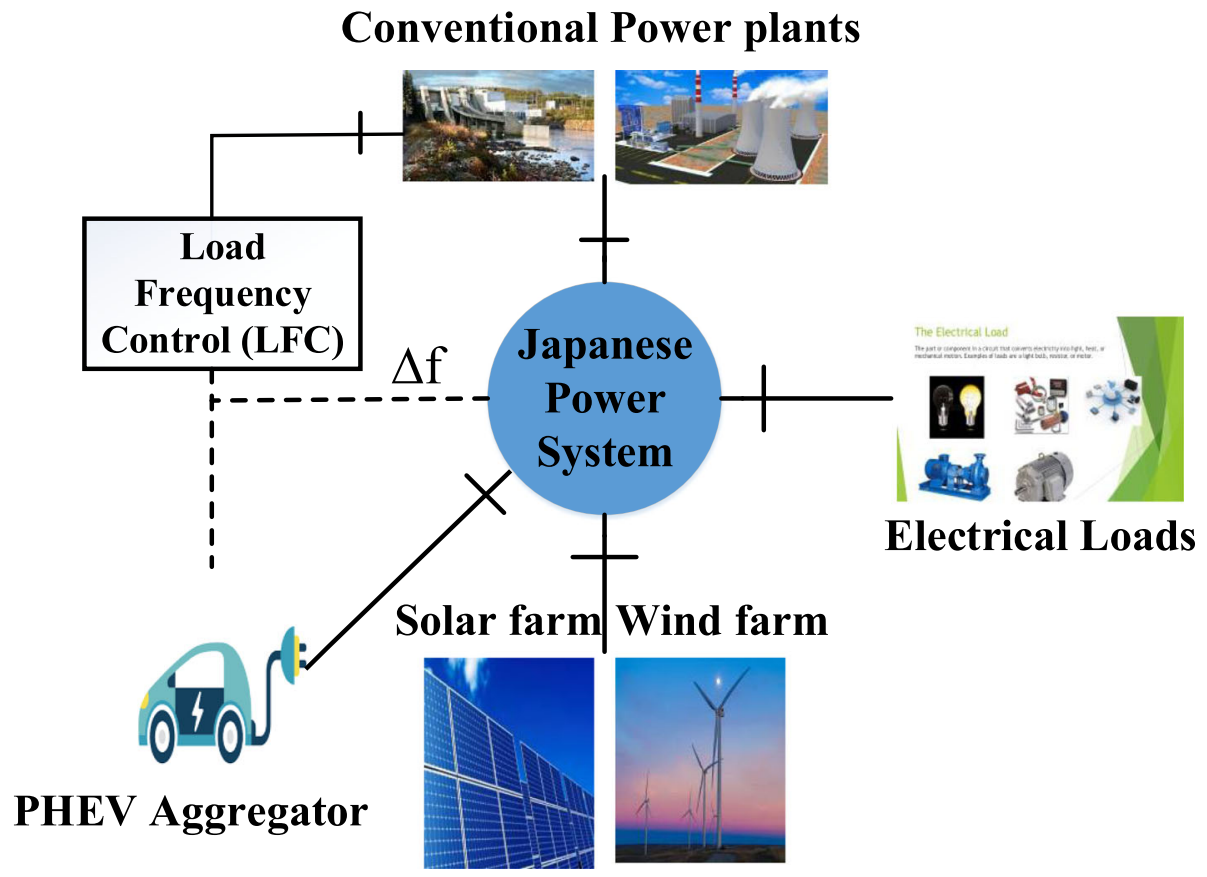

Fig. 1 Schematic model of the Japanese power system with a coordinated control approach

system. The GRC for hydro and thermal is about $3.5 \% / \mathrm{s}$ and $1.7^{*} 10^{\wedge}-2 \mathrm{puMW} / \mathrm{s}$.

In interconnected systems, the disparity between the actual and schedule generation is termed as Area Control Error (ACE):

$$
\begin{aligned}
& A C E_{1}=\beta_{1} * \Delta f_{1}+\Delta P_{t i e, 12} \\
& A C E_{2}=\beta_{2} * \Delta f_{2}+\Delta P_{t i e, 21}
\end{aligned}
$$

Where, $\beta_{1}=\frac{1}{R_{1}}+\frac{1}{R_{2}}+D_{1}$ and $\beta_{2}=\frac{1}{R_{3}}+\frac{1}{R_{4}}+D_{2}$;

Finally, the corrective signal from the controller to PHEV aggregator and governors of each area can be expressed as:

$$
\begin{aligned}
U_{c i}= & K_{P} * A C E_{i}+\frac{K_{I}}{s} * A C E_{i} \\
& +K_{D} *\left(s A C E_{i}\right) \text { where } \mathrm{i} \\
= & 1,2 .
\end{aligned}
$$

The objective of the proposed controller is to minimize the ACE, such that the frequency deviations in each area and tie-line power deviation between two areas are to be restore within the schedule limit.

\subsection{PHEVS}

The aggregated PHEV model for LFC studies is shown in Fig. 4. Input to the model is the LFC signal sent from the central load dispatching center for the proper discharging/ charging of the EVs. The $\Delta P_{P H E V}$ for discharging/charging is selected based on the control signal $\left(U_{c 1}\right)$ from the controller. In this work, the $U_{c 1}$ is determined with the help of
JAYA optimized PID controller. A bi-directional vehicle-togrid (V2G) power control PHEV is chosen for this study. In Fig. 4, the PHEV model consists of primary frequency control (PFC), LFC and battery charger. The participation factor $\left(K_{E V, i}\right)$ of each EV depends on their respective battery SOC level. Figure 5 (a) \& (b) shows the

Battery SOC vs. $K_{E V, i}$ of idle mode and discharge mode. Detailed information regarding aggregated PHEV model and participation factors is available in [21]. The $\triangle P_{P H E V}$ is controlled based on a control signal $\left(U_{c 1}\right)$, which is based on $\Delta \mathrm{f}$ of each area can be expressed as [22]:

$$
\Delta P_{P H E V}=\left\{\begin{array}{rr}
-\Delta P_{\max }, & U_{c 1}<-\Delta P_{\max } \\
\Delta P_{\max }, & U_{c 1}>\Delta P_{\max } \\
U_{c 1}, & \left|U_{c 1}\right| \leq \Delta P_{\max }
\end{array}\right.
$$

\subsection{Wind farm model}

Figure 6 depicts the aggregated wind turbine generators (WTGs) based wind farm model. In this wind farm, the total number of wind generators $(\mathrm{N})$ is divided into different

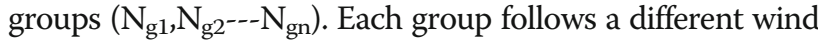
pattern. Finally, $\Delta \mathrm{P}_{\mathrm{WF}}$ can be expressed as:

$$
\Delta P_{W F}=\sum_{k, j=1}^{N} \Delta P_{W T G k} * N_{g j}
$$

In this work, GAMESA company WTG is used [23]. Based on wind speed $\left(V_{w}\right)$ and WTG output power data $\left(P_{W T G}\right)$, by using the curve fitting technique, an 


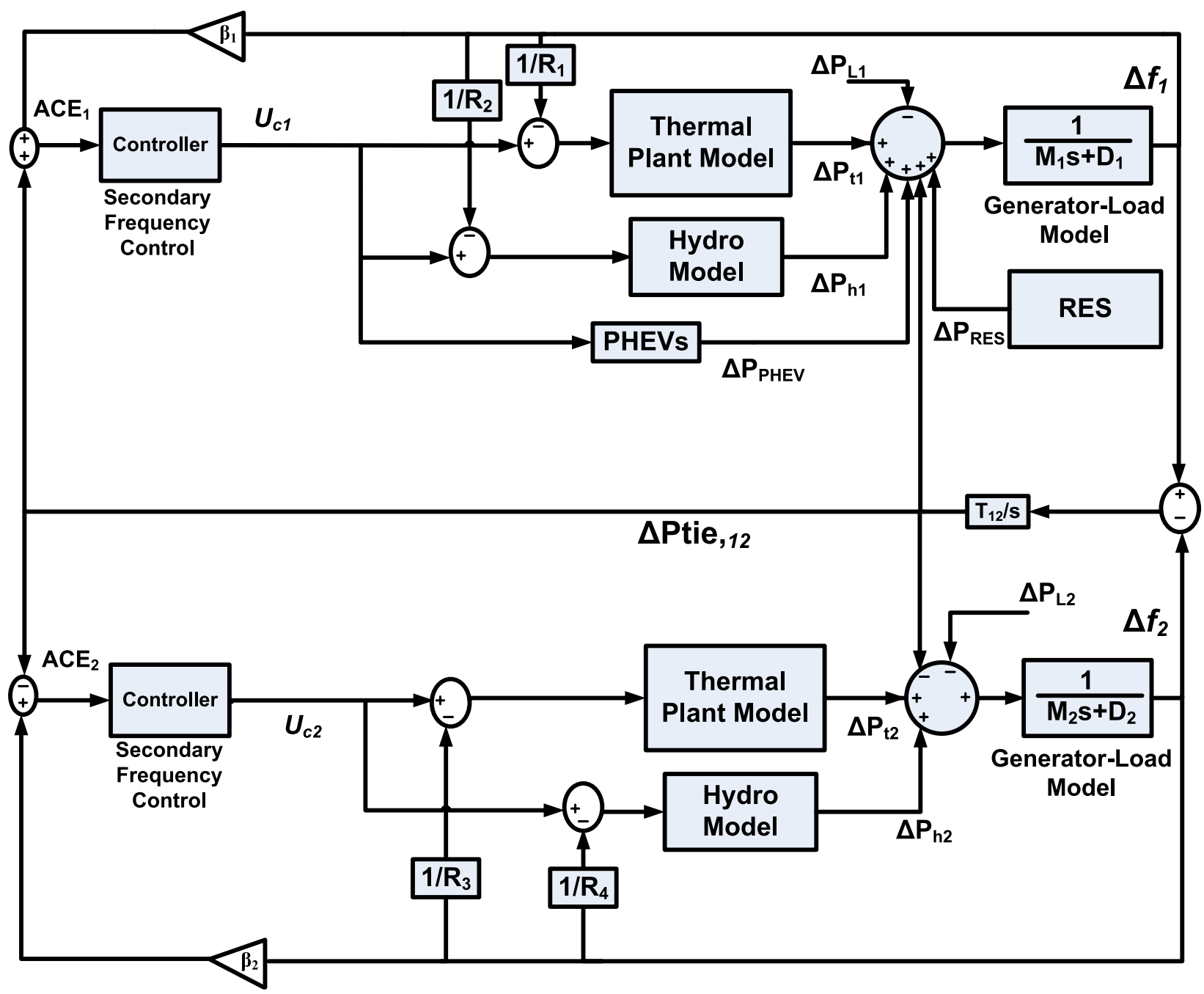

Fig. 2 Two-area power system model with RES and PHEVs

equation for $P_{W T G}$ in terms of $V_{w}$ is developed. The ' $P_{W T G}$ ' can be expressed as [23]:

$$
P_{W T G}=\left\{\begin{array}{c}
P_{\text {rated }}, \quad V_{\text {rated }} \leq V_{w} \leq V_{\text {cutout }} \\
0, V_{\text {cutin }} \leq V_{w} \leq V_{\text {rated }} \\
0.0013 V_{w}^{6}-0.046 V_{w}^{5}+0.33 V_{w}^{4}+3.68 V_{w}^{3}-51 V_{w}^{2} \\
+2.33 V_{w}+366, \text { else }
\end{array}\right.
$$

$\Delta P_{W T G}$ is obtained by differentiating the Eq.(5), which can be expressed as in Eq.(6):

$$
\Delta P_{W T G}=\left\{\begin{array}{c}
0, \quad V_{\text {rated }} \leq V_{w} \leq V_{\text {cutout }} \\
0, V_{\text {cutin }} \leq V_{w} \leq V_{\text {rated }} \\
\left(0.0078 V_{w}^{5}-0.23 V_{w}^{4}+1.32 V_{w}^{3}+11.04 V_{w}^{2}-102 V_{w}+2.33\right) * \Delta V_{w}, \text { else }
\end{array}\right.
$$

\subsection{PV model}

The PV array consists of a combination of modules in series and parallel, and this combination depends on the required voltage and current ratings of the solar farm. The $\mathrm{P}_{\mathrm{PV}}$ varies due to either change in irradiation (or) load current. In present LFC studies, it is assumed that the $\mathrm{P}_{\mathrm{PV}}$ changes only due to irradiation. $P_{\text {solar }}$ can be computed using (Eq.7).

$$
P_{\text {solar }}=P_{P V} * \frac{G}{G_{S T C}} *\left(1+K_{t} *\left[T_{a}+0.0256 * G * \Delta G-T_{S T C}\right]\right)
$$

The $\Delta P_{\text {solar }}$ based on the change in irradiation can be computed using the Eq. 8:

$$
\begin{aligned}
\Delta P_{\text {solar }} & =\frac{P_{P V}}{G_{S T C}} *\left(\Delta G+K_{t}\left[\Delta G * T_{a}+G * \Delta T_{a}\right.\right. \\
& \left.\left.+0.0512 * G * \Delta G-T_{S T C} * \Delta G\right]\right) ; \text { Where }, \Delta T_{a}=0 \\
\Delta P_{S F} & =\Delta P_{\text {solar }} * \mathrm{~N}
\end{aligned}
$$

The total change in RES output power (In Fig. 2, $\Delta P_{R E S}$ ) can be expressed as:

$$
\Delta P_{R E S}=\Delta P_{W F}+\Delta P_{S F}
$$



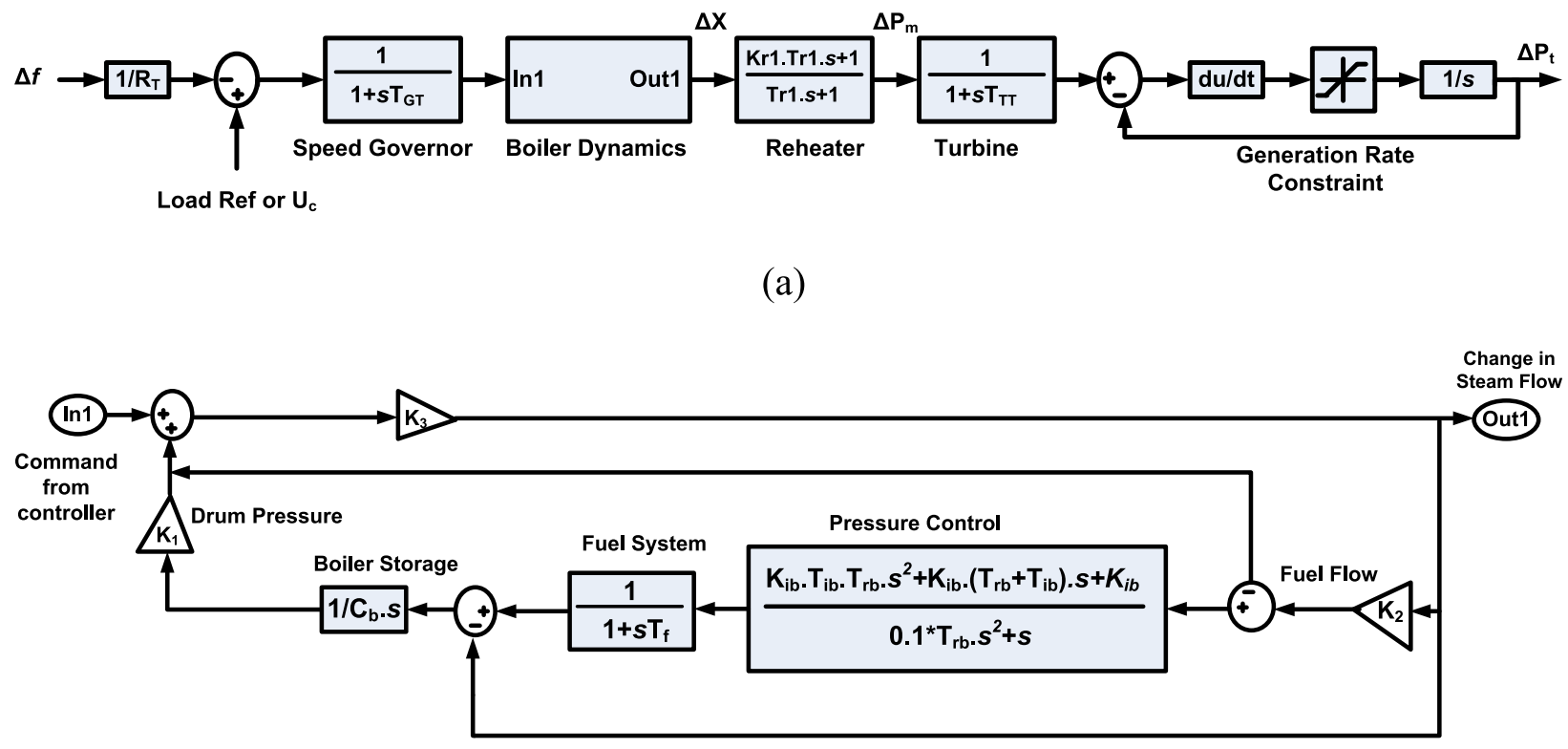

(b)

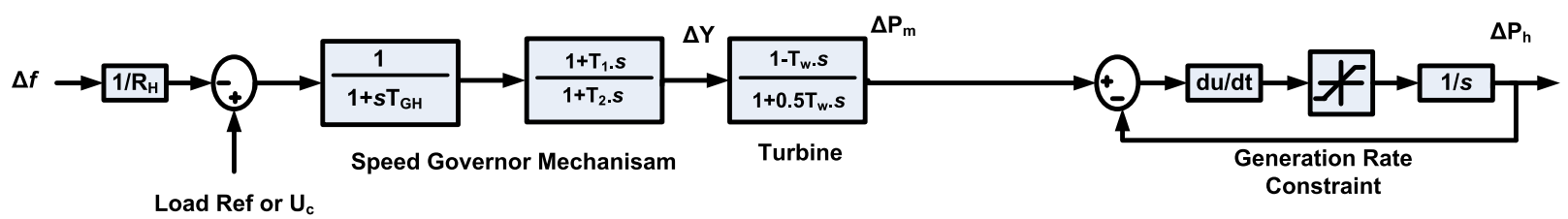

$R_{T}, R_{H}$ : Speed regulation constant of thermal and hydro unit; $T_{G T}, T_{G H}$ : Governor time constant of thermal and hydro unit; $T_{\mathrm{rr}}$ : Turbine reheat time constant; $\mathrm{K}_{\mathrm{r} \mathrm{r}}$ : Coefficient of re-heat; $\mathrm{T}_{\mathrm{TT}}$ : Time constant of steam turbine; $\Delta \mathbf{P}_{\mathrm{m}}$ : change in mechanical power; $\Delta \mathrm{P}_{\mathrm{t}}$ : change in output power of thermal unit; $\mathrm{T}_{1}:$ Hydro governor rest time; $\mathrm{T}_{2}:$ Transient droop time constant; $\mathrm{T}_{\mathrm{W}}$ : Water turbine time constant; $\mathrm{T}_{\mathrm{TH}}$ : Time constant of hydro turbine; $\Delta \mathrm{P}_{\mathrm{h}}$ : change in output power of hydro unit

(c)

Fig. 3 Mathematical Modeling of a) Aggregated thermal unit b) Hydro unit c) Boiler dynamics

\section{Proposed method}

In the literature, several authors proposed various swarm-intelligence techniques for LFC problem $[3,7,8$, 24]. But, the problem with these swarm-intelligence techniques is their performance highly depends on algorithm-specific parameters. For example, cognitive parameters $\left(\mathrm{c}_{1}, \mathrm{c}_{2}\right)$ and inertia weight $(\mathrm{w})$ in case of PSO; crossover, mutation \& parent selection in case of GA. Likewise, the other algorithms such as flower pollination algorithm (FPO), backstepping algorithm,

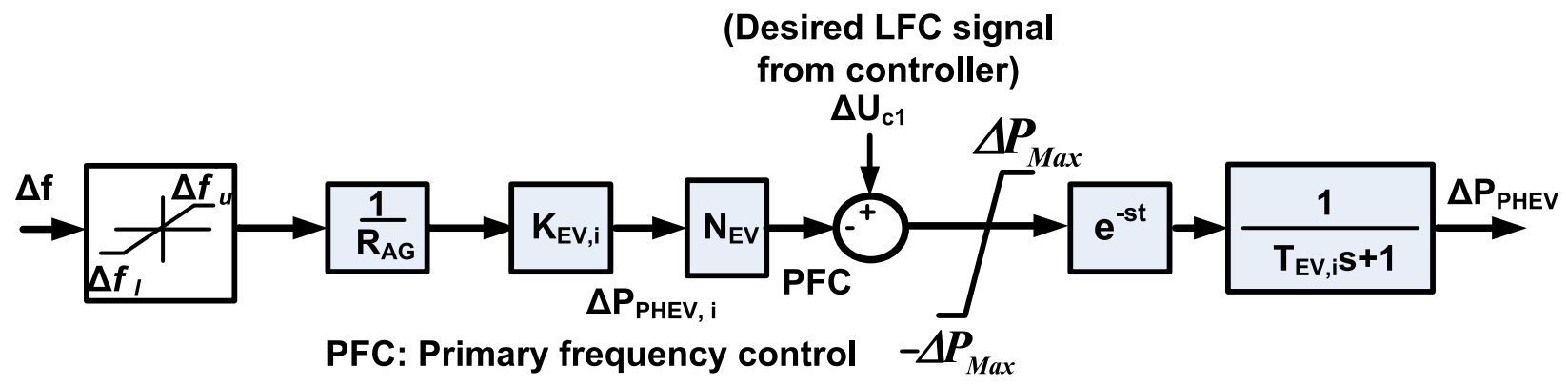

Fig. 4 EV aggregator structure 


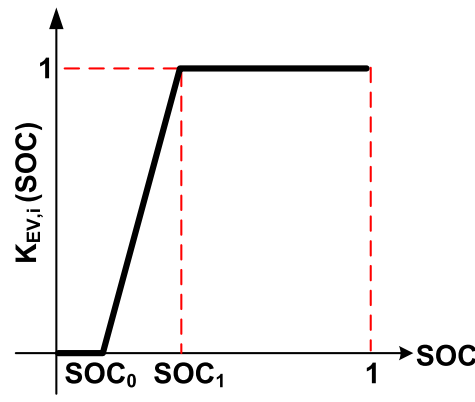

(a)

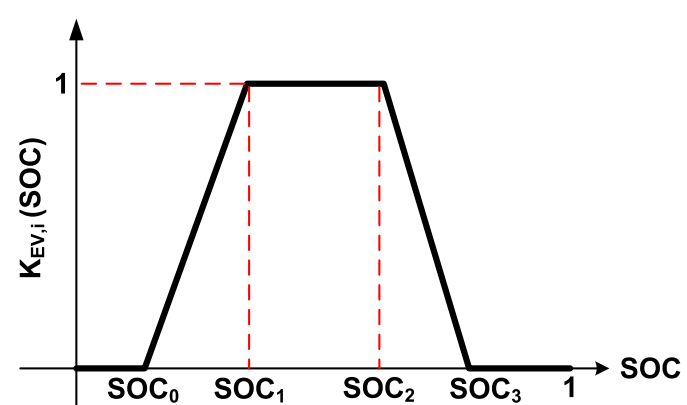

(b)

Fig. $5 \mathrm{SOC}$ vs. $\mathrm{K}_{\mathrm{EV}, \mathrm{i}}$ a) In idle Mode, b) In discharge Mode

differential evolution (DE), bat algorithm, grey wolf optimization, etc., need the tuning of their respective parameters. Improper selection or tuning of these parameters may not give the optimal solution. To overcome this problem, an algorithmic-specific parameters free technique named Jaya algorithm (JA) is adopted to tune the gains of PID controller for LFC problem.

Jaya algorithm was introduced by R.V. Rao in the year 2016 [25], inspired by the humanoid or animal activities. As a biological nature, all the humans or animals in a population are different in many cases. But, all of them are inspires by the elite or firm member of the population and, try to away from the lazy or weak member of the population. By mimicking this nature, throughout this algorithm, a candidate solution moves away the worst solution and in the meantime, it moves towards the best solution. This algorithm has been successfully applied to several engineering problems, because of its fast convergence and simplicity [26, 27].

Let $\mathrm{p}$ be the population size $(\mathrm{m}=1,2-\mathrm{p}), \mathrm{n}$ be the number of variables $(v=1,2--n)$ and $\operatorname{ITAE}(13)$ is the fitness function to be minimized. Based on the ITAE, the best solution in the population is considered as $X_{\text {best }}$ and the worst solution is considered as $\mathrm{X}_{\mathrm{worst}} \cdot \mathrm{X}_{\mathrm{v}, \mathrm{m}, \mathrm{i}}$ is the value of $\mathrm{v}^{\text {th }}$ variable for the $\mathrm{m}^{\text {th }}$ candidate in the $\mathrm{i}^{\text {th }}$ iteration. Then the updated

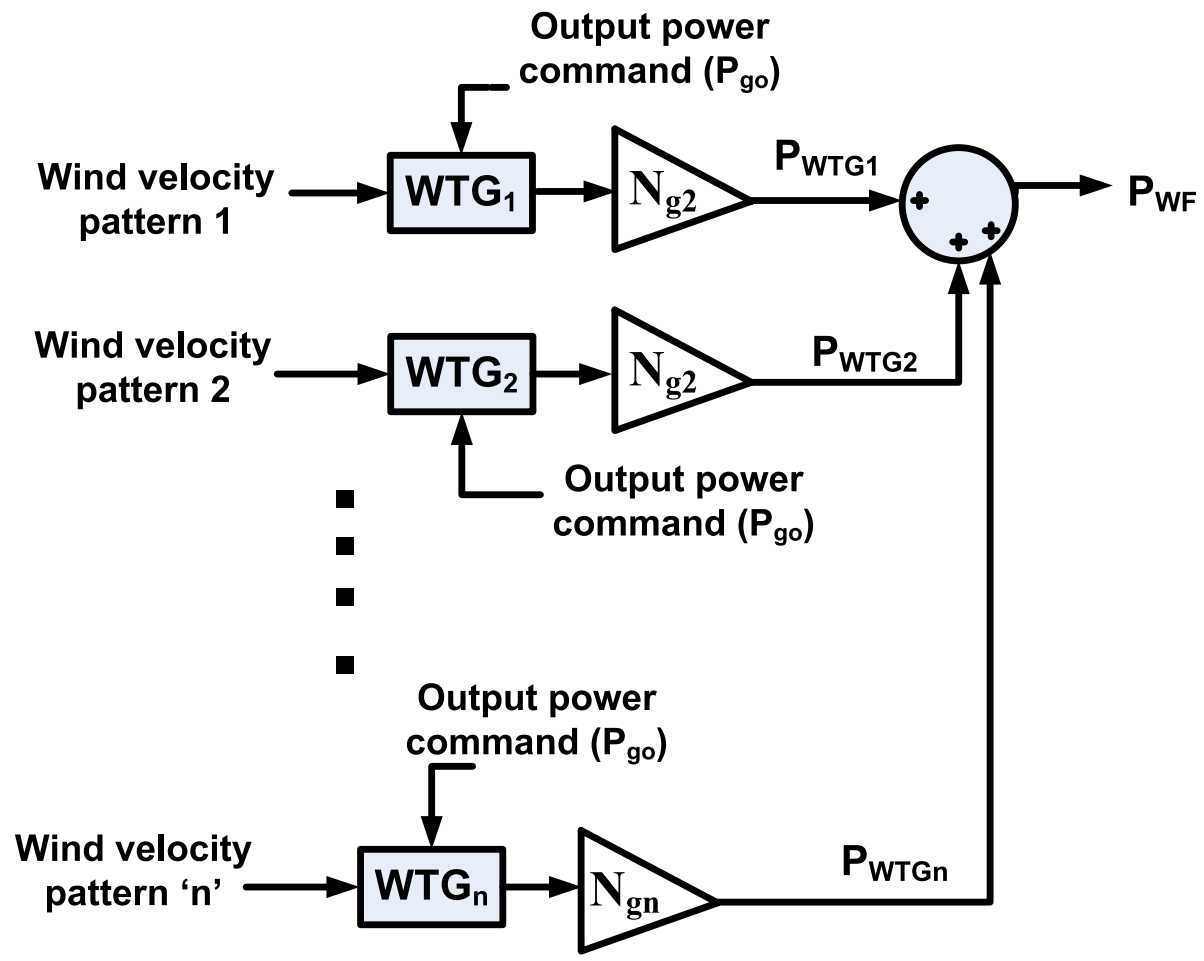

Fig. 6 Aggregated model of the wind farm 
value of each variable $X_{v, m, i}^{\prime}$ in the population can be expressed as[33]:

$$
X_{v, m, i}^{\prime}=X_{v, m, i}+\operatorname{rand}_{1} *\left(X_{v, b e s, i}-\left|X_{v, m, i}\right|\right)-\operatorname{rand}_{2} *\left(X_{v, \text { wors }, i}-\left|X_{v, m, i}\right|\right)
$$

In Eq.(11) it is observable that, a member of the population is always moving towards the best solution (' + ' indication) and away from the worst solution('-' indication). Moreover, from equation it is clear that, the proposed algorithm doesn't depend on any algorithmic specific parameters unlike other algorithms. The updated value of the member in the population $\left(X_{v, m, i}^{\prime}\right)$ is accepted only when its value is better than old value $\left(X_{v}, m, i\right) . \operatorname{rand}_{1}$ and $\operatorname{rand}_{2}$ indicates the random numbers between 0 and 1 .

$$
X_{v, m, i}^{\prime}=\left\{\begin{array}{c}
X_{v, m, i}, \quad \operatorname{ITAE}\left(X_{v, m, i}\right)>\operatorname{ITAE}\left(X_{v, m, i}^{\prime}\right) \\
X_{v, m, i}^{\prime}, \quad \text { Otherwise }
\end{array}\right.
$$

\subsection{Sequential steps to tune the proposed PID controller with JAYA algorithm}

Step 1: A random population is generated by initializing the controller parameters $\left(K_{P}, K_{I}, K_{D}\right)$ within the limit 0.01 and 5.0. As there are 6 controller parameters related to two PID controllers, so the population size is considered as $50 \times 6$.

Step 2: The designed Simulink model is run by implementing the integral absolute error (ITAE) as fitness function (Eq.13) to assess the fitness values of the defined population.

$$
\begin{gathered}
\operatorname{Minimize}(F F)=\mathrm{ITAE}=\text { minimization of } \int_{0}^{t_{\text {sin }}} t * \\
\left(K_{P} *\left(\left|A C E_{1}\right|+\left|A C E_{2}\right|\right)+\frac{K_{I}}{s} *\left(\left|A C E_{1}\right|+\left|A C E_{2}\right|\right)\right. \\
\left.+s * K_{D} *\left(\left|A C E_{1}\right|+\left|A C E_{2}\right|\right)\right) * \mathrm{dt}
\end{gathered}
$$

Where, $\left|A C E_{1}\right|=\left|\Delta f_{1}\right|+\left|\Delta P_{\text {tie, } 12}\right|,\left|A C E_{2}\right|=\left|\Delta f_{2}\right|+\mid$ $\Delta P_{\text {tie, 21 }} \mid \& t_{\text {sim }}=$ Total simulation time.

Step 3: In the population, identify the best and worst candidates using Eq.(13).

Step 4: Update each candidate position with respect to the best and worst candidates using Eq.(11).

Step 5: If the updated candidate $\left(X_{v, m, i}^{\prime}\right)$ is better than the old one $\left(X_{v, m, i}\right)$; replace the old one or else keep the old one using Eq.(12).

Step 6: Repeat steps (2) to (5) until the maximum number of iterations (50) is achieved.

Step 7: if iterations =iterations maximum, the best member of the population will be treated as the best set of controller parameters.
Figure 7 illustrates the flow chart for the summarized steps of the JA-PID controller.

\section{Results and discussion}

The simulated model of the selected test system has been formulated by the help of MATLAB (R2015a) software, core i7 processor with 8 GB RAM computer. The test system parameters are listed in Appendix (8.1-8.3). The performance of the proposed coordinated strategy is compared with various other strategies in literature. Moreover, the performance of the selected JAYA algorithm is compared with various other controllers in the literature like GWO-PID, PSO-PID, GA-PID and Z-N PID controller under various critical operating scenarios.

\subsection{Scenario 1 (In Fig. 2, Area 1 is assumed as an isolated area)}

Objective: To demonstrate the superiority of the proposed control strategy in improving the dynamic response of the system over a load and RES perturbations.

Test Condition: A step change of 0.025 p.u. in load demand \& 0.1 p.u. in RES at an instant of $20 \mathrm{~s}$ and $130 \mathrm{~s}$ respectively.

Figure 8 shows the dynamic response of area 1 (as an isolated area) with various controllers for scenario 1 . The quantitative analysis of Fig. 8 is given in Table 1.The optimized PID parameters with various optimization techniques are given in Table 2.

\subsection{Scenario 2 (In Fig. 2, simultaneous load perturbations} are considered in area $1 \&$ area 2 )

Objective: To demonstrate the superiority of the proposed control strategy in improving the settling time and overshoot for step load disturbances in areal and area 2 simultaneously at $5 \mathrm{~s}$.

Test condition: A step change of 0.1 p.u. and 0.08 p.u. in the load demand of area 1 and area 2 at $5 \mathrm{~s}$ respectively.

Figure 9 (a), (b) \& (c) shows the frequency response of area 1 , area 2 and tie-line power deviations between area1 and area 2 respectively. The quantitative analysis of Fg.9 (a)-(c) is given in Table 3. For better view of results, the proposed controller is compared with recent approaches in the literature by ignoring Zigler-Nicholas tuned PID controller.

4.3 Scenario 3 (In Fig. 2, the real-time load, solar and wind power fluctuations are considered simultaneously) Objective: To demonstrate the impact of PHEVs in minimizing ACEof a renewable penetrated power system. For this scenario, three control mechanisms are considered. These are:

1. Without any Load Frequency Control (LFC).

2. With JA-PID controller without any PHEVs. 


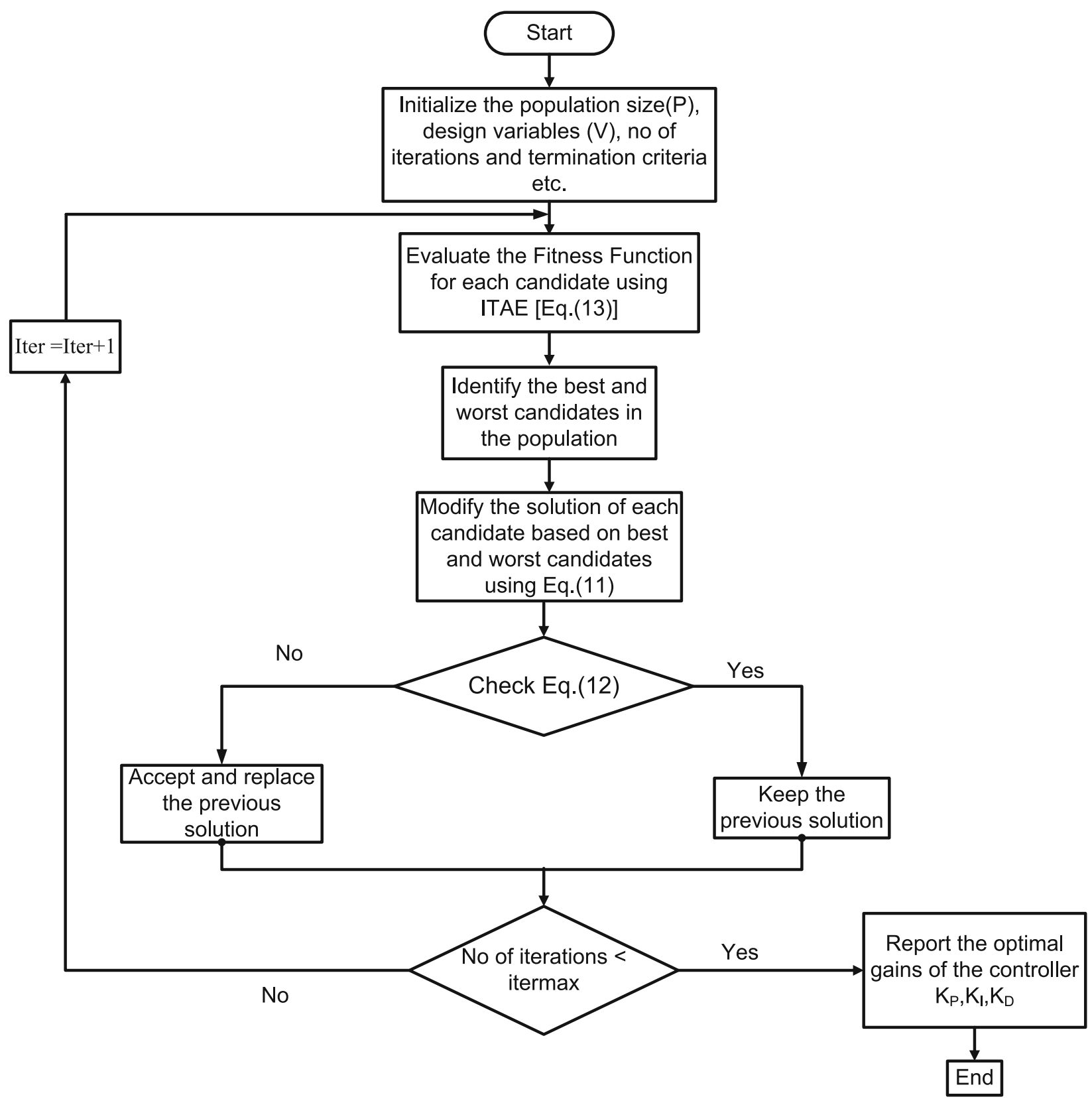

Fig. 7 Flowchart of JA-PID controller

3. Proposed coordinated JA-PID controller with PHEV aggregator.

Fig. 10 (a)-(b) depicts a real-time wind farm and solar farm output power perturbations in area 1 respectively. Figure 10 (c) depicts real-time load disturbances in area 1 . Figure $10(\mathrm{~d}),(\mathrm{e})$ and $(\mathrm{f})$ shows the frequency response of area 1 , area 2 and tie-line power deviations between area1 and area 2 respectively. From Fig. 10 (d), (e) and (f), using the PHEVs $c$ in LFC, the frequency stability of the power system was enhanced significantly. The system frequency and the tie-line power flow deviations are greatly reduced by the proposed control strategy. The dynamic response of various control mechanisms in terms of ITAE (as mentioned in Eq.13) are given in Table 4.

\subsection{Scenario 4 (The same conditions as mentioned in scenario 3 )}

Objective: To demonstrate the impact of coordinated control of conventional power sources and PHEVs in minimizing ACE of a renewable penetrated power system. For this scenario, two control mechanisms are considered. These are: 


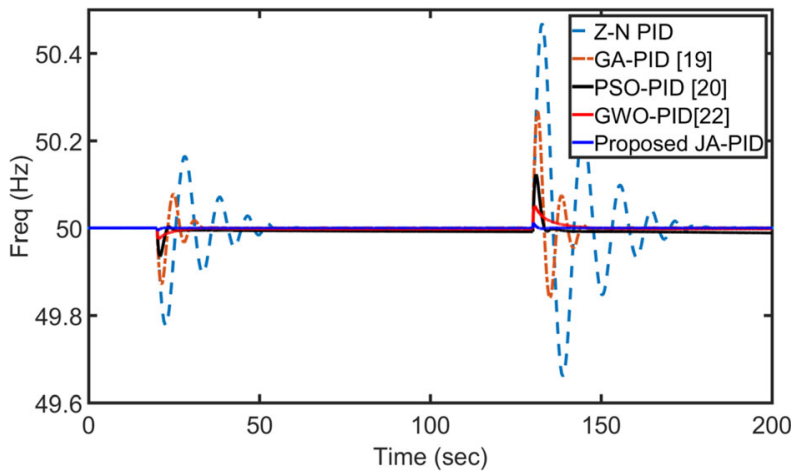

Fig. 8 Scenario 1 frequency deviation response

1. PHEVs in frequency regulation but, no coordination between conventional power sources (CPS) and PHEVs.(i.e., PHEVs are included in primary frequency regulation).

2. Coordinated control between CPS and PHEVs.(i.e., PHEVs are included in secondary frequency regulation).

Figure 11 (a)-(b) shows the frequency response of area 1 and area 2 and Fig. 11 (c) shows the tie-line power deviations between area 1 and area 2 respectively. The dynamic response of various control mechanisms in terms of ITAE (as mentioned in Eq. 13) are given in Table 5.

\section{Summary of simulation results}

1. From scenario $1 \& 2$, the simulation results reveal that the proposed JA-PID controller is improving the dynamic response of the system (as an isolated area) for a step load disturbance over recent and standard controllers in literature.

2. From scenario 3, it is clear that the interaction of PHEVs reducing the system error (ACE) significantly. On the other hand, CPS alone is

Table 1 Dynamic response of various controllers for scenario 1

\begin{tabular}{lllll}
\hline Methods & \multicolumn{4}{l}{ Performance indices } \\
\cline { 2 - 5 } & $\begin{array}{l}\text { Peak } \\
\text { Undershoot } \\
(\mathrm{Hz})\end{array}$ & $\begin{array}{l}\text { Settling time } \\
(\mathrm{sec})\end{array}$ & $\begin{array}{l}\text { Peak } \\
\text { overshoot } \\
(\mathrm{Hz})\end{array}$ & $\begin{array}{l}\text { Settling Time } \\
(\mathrm{Sec})\end{array}$ \\
\hline Z-N PID & 49.79 & 30 & 50.4 & 33 \\
GA-PID & 49.85 & 20 & 50.2 & 21 \\
{$[19]$} & & 17 & 50.12 & 18 \\
$\begin{array}{l}\text { PSO-PID } \\
{[20]}\end{array}$ & 49.93 & 15 & 50.08 & 15 \\
$\begin{array}{l}\text { GWO-PID } \\
{[22]}\end{array}$ & 49.975 & 15 & & \\
JAYA-PID & $\mathbf{4 9 . 9 9}$ & $\mathbf{1 0}$ & $\mathbf{5 0 . 0 5}$ & $\mathbf{1 1 . 5}$ \\
\hline
\end{tabular}

Table 2 Optimized PID parameters with different approaches

\begin{tabular}{llll}
\hline Methods & \multicolumn{3}{l}{ Traditional LFC PID parameters } \\
\cline { 2 - 4 } & $\mathrm{K}_{\mathrm{P}}$ & $\mathrm{K}_{\mathrm{I}}$ & $\mathrm{K}_{\mathrm{D}}$ \\
\hline Z-N PID & 0.06 & 1.13 & 0.1 \\
GA-PID[19] & 0.504 & 1.51 & 1.16 \\
PSO-PID[20] & 0.3064 & 2.3027 & 0.7361 \\
GWO-PID[22] & 0.1639 & 1.9193 & 0.9317 \\
JAYA-PID & $\mathbf{0 . 0 4 8 5}$ & $\mathbf{2 . 1 3 2 1}$ & $\mathbf{0 . 2 6 4 6}$ \\
\hline
\end{tabular}

unable to maintain the system frequency within the tolerable limits (i.e. $50 \pm 0.2 \mathrm{~Hz}$ ).

3. From scenario 4 , the simulation results reveal that the proposed coordinated approach (i.e. coordination of CPS \& PHEVs in secondary frequency control) is minimizing the system error (ACE) to a great extent

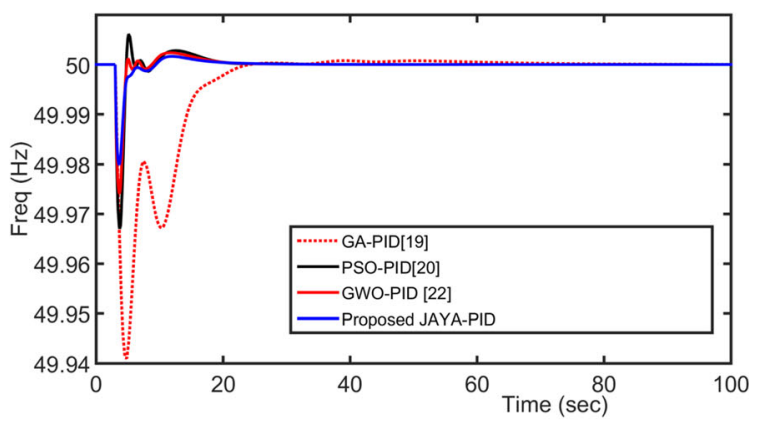

(a)

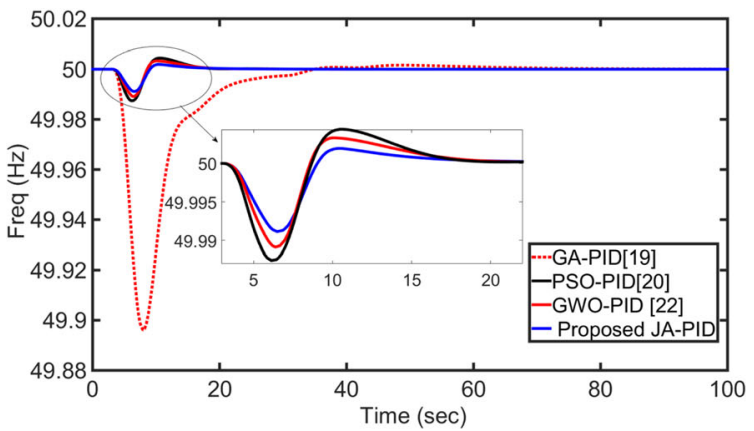

(b)

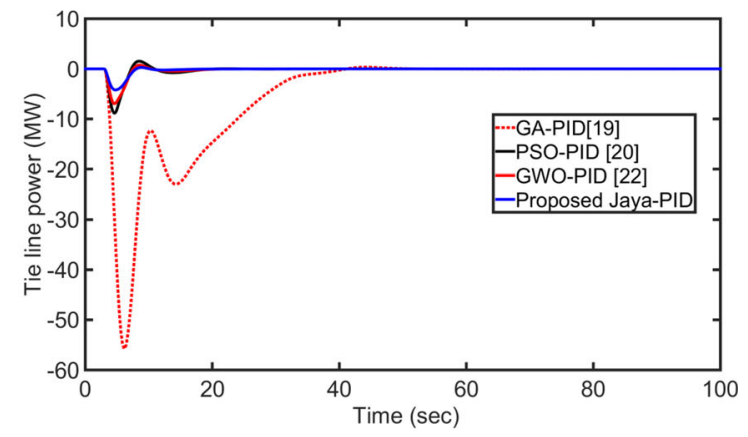

(c)

Fig. 9 (a), (b) $\Delta f_{1}$ and $\Delta f_{2}$ for scenario 2 , (c) $\Delta P_{\text {tie, } 12}$ for scenario 2 
Table 3 Dynamic response of various controllers for scenario 2 instead of optimized PID parameters with different approaches

\begin{tabular}{|c|c|c|c|c|c|c|}
\hline \multirow[t]{3}{*}{ Methods } & \multicolumn{6}{|c|}{ Performance indices } \\
\hline & \multicolumn{2}{|l|}{ Area 1} & \multicolumn{2}{|l|}{ Area 2} & \multicolumn{2}{|c|}{$\begin{array}{l}\text { Tie-line power } \\
\text { deviation }\end{array}$} \\
\hline & $\begin{array}{l}\text { Peak } \\
\text { Undershoot } \\
(\mathrm{Hz})\end{array}$ & $\begin{array}{l}\text { Settling } \\
\text { Time } \\
\text { (sec) }\end{array}$ & $\begin{array}{l}\text { Peak } \\
\text { Undershoot } \\
(\mathrm{Hz})\end{array}$ & $\begin{array}{l}\text { Settling } \\
\text { Time } \\
\text { (sec) }\end{array}$ & $\begin{array}{l}\text { Peak } \\
\text { Undershoot } \\
(\mathrm{MW})\end{array}$ & $\begin{array}{l}\text { Settling } \\
\text { Time } \\
(\mathrm{sec})\end{array}$ \\
\hline $\begin{array}{l}\text { GA-PID } \\
{[19]}\end{array}$ & 49.941 & 44 & 49.895 & 52 & 55 & 45 \\
\hline $\begin{array}{l}\text { PSO-PID } \\
{[20]}\end{array}$ & 49.969 & 24 & 49.987 & 21.5 & 9 & 19.5 \\
\hline $\begin{array}{l}\text { GWO- } \\
\text { PID [22] }\end{array}$ & 49.976 & 21 & 49.989 & 18 & 7 & 17 \\
\hline $\begin{array}{l}\text { JAYA- } \\
\text { PID }\end{array}$ & 49.98 & 18 & 49.9915 & 15 & 4 & 11 \\
\hline
\end{tabular}

over PHEVs in primary frequency control (i.e. CPS and PHEVs are not incoordination).

\section{Conclusion}

This work presented a novel optimal LFC scheme coordinated with PHEVs to enhance the frequency response of a renewable penetrated power system. A recently developed swarm-intelligent technique named JAYA algorithm is applied to optimize the PID controller in the aim of both PHEVs output power control and frequency regulation of the power system. The impact of RES on frequency control has been analyzed, and after that to exhibit the capability of the proposed approach, a comparative study with some standard and recent optimization techniques was performed.

In scenario 1 and scenario 2, the dynamic response of the system with the proposed approach in terms of settling time and undershoot/overshoots are studied. In scenario 3 and scenario 4, the frequency deviation response of RES penetarted power system have been anayzed with optimized PID controller and PHEVs in PFC and LFC loops are studied. Further, the presence of PHEVs enhanced the capacity of LFC in the presence of RES. Finally, the presence of PHEVs in the secondary loop of LFC and coordinating with conventional power sources is significantly improving the system dynamic response over without PHEVs and with PHEVs in the primary loop.

\section{Nomenclature}

\subsection{For the two-area power system}

$M_{1}, M_{2}$ Equivalent inertia of the area1 \& area 2.

$D_{1}, D_{2}$ Equivalent load damping coefficient of the area1 \& area 2 .

$\Delta f_{1}, \Delta f_{2}$ Frequency deviation of the area1 \& area 2.

$U_{c 1}, U_{c 2}$ Command signal from the controller to the governor in area1 \& area 2.

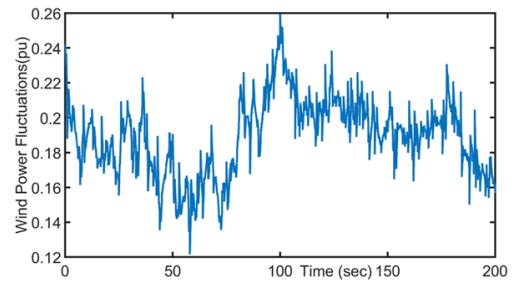

(a)

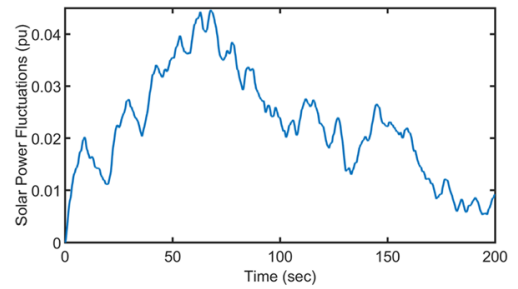

(b)

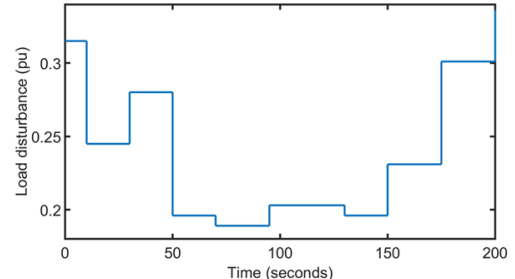

(c)

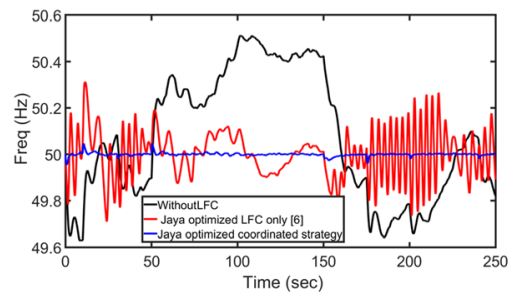

(d)

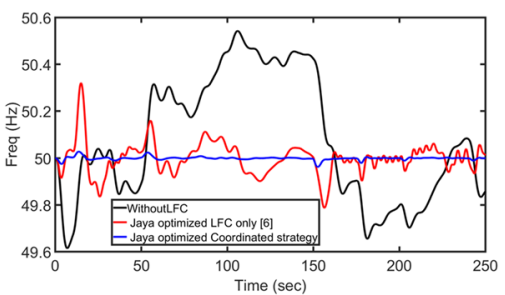

(e)

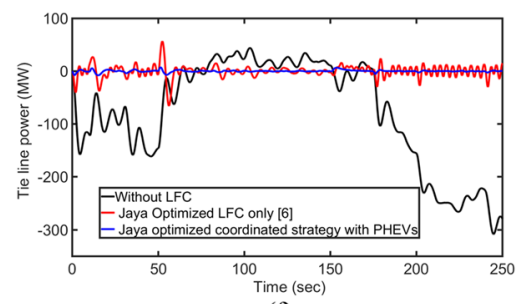

(f)

Fig. 10 a) Wind farm power deviations, b) solar power deviations, c) Load profile, d), e) $\Delta f_{1}$ and $\Delta f_{2}$ for scenario 3 f) $\Delta P_{\text {tie, } 12}$ for scenario 3 
Table 4 Calculated values of fitness function (13) for scenario 3

\begin{tabular}{llll}
\hline Scenario & $\begin{array}{l}\text { Without } \\
\text { any LFC } \\
\text { Scheme }\end{array}$ & $\begin{array}{l}\text { With JAYA optimized } \\
\text { LFC without any PHEV } \\
\text { Aggregator }\end{array}$ & $\begin{array}{l}\text { With JAYA optimized } \\
\text { LFC coordinated with } \\
\text { PHEV Aggregator }\end{array}$ \\
\hline Scenario 3 & 0.28 & 0.092 & $\mathbf{0 . 0 0 0 6}$
\end{tabular}

$\frac{1}{R_{1}}, \frac{1}{R_{3}}$ droop characteristics of the aggregated thermal unit in area $1 \&$ area 2.

$\frac{1}{R_{2}}, \frac{1}{R_{4}}$ droop characteristics of the aggregated hydro unit in area $1 \&$ area 2.

$T_{12}$ Synchronizing coefficient.

$\beta_{1}, \beta_{2}$ Equivalent frequency bias factor in area $1 \&$ area 2.

$\Delta P_{L 1}, \Delta P_{L 2}$ Change in load profile in the area1 \& area 2.

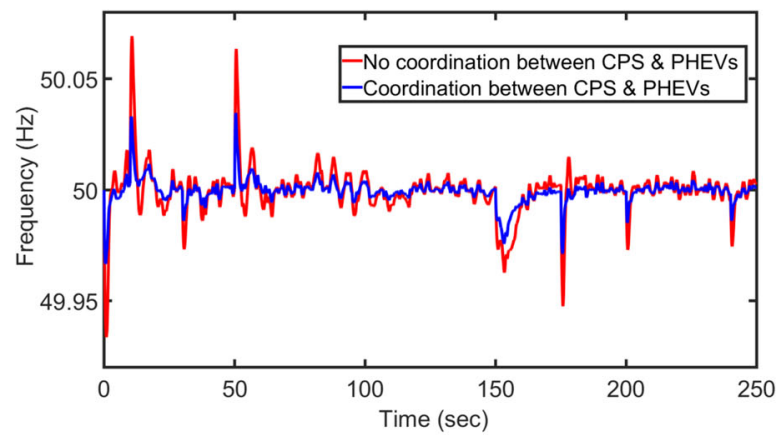

(a)

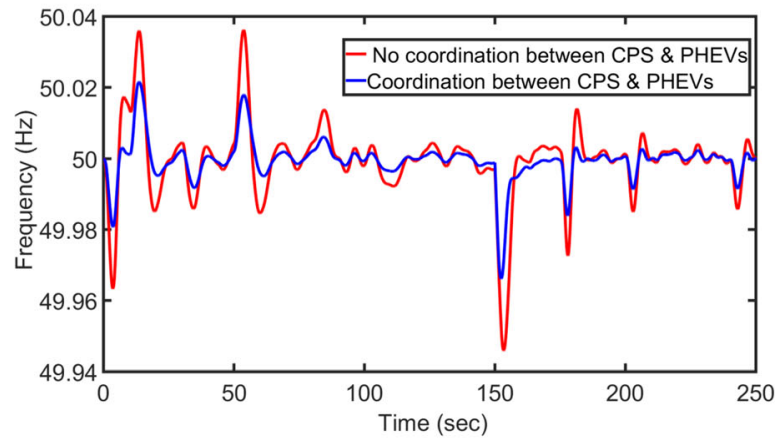

(b)

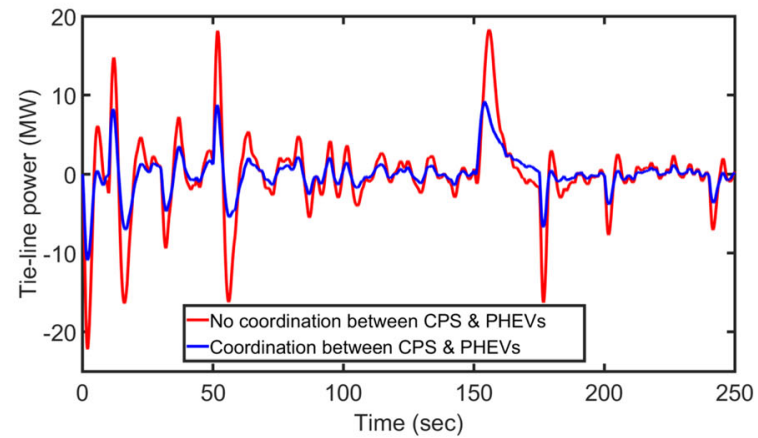

(c)

Fig. 11 a), b) $\Delta f_{1}$ and $\Delta f_{2}$ for scenario 4 c) $\Delta P_{t i e, 12}$ for scenario 4
Table 5 Calculated values of fitness function (13) for scenario 4

\begin{tabular}{lll}
\hline Scenario & $\begin{array}{l}\text { With JAYA optimized LFC, but } \\
\text { PHEV aggregator in primary } \\
\text { frequency control }\end{array}$ & $\begin{array}{l}\text { With JAYA optimized LFC } \\
\text { coordinated with PHEV } \\
\text { Aggregator }\end{array}$ \\
\hline Scenario 4 & 0.0018 & $\mathbf{0 . 0 0 0 6}$
\end{tabular}

$\Delta P_{t i e, 12}$ tie-line power deviation between area $1 \&$ area 2.

$\Delta P_{t 1}, \Delta P_{t 2}$ Change in the output power of the aggregated thermal unit in area1 \& area 2 .

$\Delta P_{h 1}, \Delta P_{h 2}$ Change in the output power of the aggregated hydro unit in area1 \& area 2.

$A C E_{1}, A C E_{2}$ Area control error in area 1 \& area 2.

$\triangle P_{R E S}$ Change in the RES output power.

\subsection{For the PHEVs}

$U_{c i}$ Control signal received by the PHEV aggregator from optimized PID controller.

$\triangle P_{P H E V}$ Change in PHEV aggregator output power.

$\Delta P_{\text {Max }}$ The maximum allowable discharging power from the EV aggregator.

$-\Delta P_{\text {Max }}$ The maximum allowable charging power to the EV aggregator.

$e^{-s T}$ Communication delay between PHEV aggregator and LFC-control center.

$\frac{1}{R_{a v}}$ Droop characteristics of the PHEV aggregator.

$K_{E V, i}$ Participation factor of each PHEV.

$N_{E V}$ Number of PHEVs in the aggregator.

$T_{E V, i}$ Time constant of the PHEV.

soc. state of charge.

\subsection{For the wind farm}

$\Delta P_{W F}$ Change in the wind farm output.

$P_{W T G}$ WTG output power.

$P_{\text {rated }}$ The rated output power of WTG.

$\Delta P_{W T G k}$ Change in the $\mathrm{K}^{\text {th }}$ Wind generator output power.

$V_{W}$ Wind velocity.

$k$ Number of WTGs in each group.

j Number of WTG aggregator in wind farms.

$N_{g j}$ Number of WTGs in the $\mathrm{j}^{\text {th }}$ group.

\subsection{For solar farm}

$G_{S T C}$ Reference sun irradiance $\left(1000 \mathrm{w} / \mathrm{m}^{2}\right)$.

$\mathrm{G}$ current sun irradiance.

$\triangle P_{S F}$ Change in the solar farm output.

$P_{P V}$ Panel rated power at standard operating conditions.

$T_{a}$ Ambient Temperature.

$T_{S T C}$ `Reference temperature (i.e. $25^{0 C}$ ).

$P_{\text {solar }}$ Solar output power of a group.

$\mathrm{N}$ No of groups in the solar farm. 


\section{Appendix}

\subsection{IEE-Japan-East-107-Bus Data}

$\mathrm{M}_{1}=8.85 \mathrm{~s} ; \mathrm{M}_{2}=9.2 \mathrm{~s}-; \mathrm{D}_{1}, \mathrm{D}_{2}=0.04 \mathrm{puMW} / \mathrm{Hz} ; \beta_{1}, \beta_{2}=$ $0.4566 \mathrm{puMW} / \mathrm{Hz}$;

$$
\mathrm{R}_{1}-\mathrm{R}_{4}=2.4 \mathrm{~Hz} / \mathrm{puMW} ; \mathrm{T}_{12}=5 \text {. }
$$

\subsection{Thermal and Hydro Generator Data}

$\mathrm{T}_{\mathrm{TT}}=0.3 \mathrm{~s} ; \mathrm{T}_{\mathrm{r} 1}=10 \mathrm{~s} ; \mathrm{T}_{\mathrm{GT}}=0.2 \mathrm{~s} ; \mathrm{K}_{\mathrm{r} 1}=0.333 ; \mathrm{K}_{\mathrm{ib}}=0.03$; $\mathrm{K}_{1}, \mathrm{~K}_{2}, \mathrm{~K}_{3}=0.85,0.095,0.92 ; \mathrm{C}_{\mathrm{b}}=200 ; \mathrm{T}_{\mathrm{rb}}=69 \mathrm{~s} ; \mathrm{T}_{\mathrm{ib}}=26 \mathrm{~s}$; $\mathrm{T}_{\mathrm{f}}=10 \mathrm{~s} ; \mathrm{R}_{\mathrm{T}}, \mathrm{R}_{\mathrm{H}}=2.4 \mathrm{~Hz} /$ puMW; $\mathrm{T}_{1}=0.513 \mathrm{~s} ; \mathrm{T}_{2}=10 \mathrm{~s} ;$ $\mathrm{T}_{\mathrm{w}}=1 \mathrm{~s} ; \mathrm{T}_{\mathrm{GH}}=0.1 \mathrm{~s}$.

\subsection{PHEV Data}

$\Delta f_{l}, \Delta f_{u}=$ Lower and upper frequency dead bands $(-100$ $\mathrm{mHz} \& 100 \mathrm{mHz}) ; \mathrm{R}_{\mathrm{av}}=2.4 \mathrm{~Hz} / \mathrm{puMW} ; \mathrm{K}_{\mathrm{EV}, \mathrm{i}}$ (average) $=$ $0.55, \mathrm{~T}_{\mathrm{EV}, \mathrm{i}}=0.1$.

\section{Acknowledgments}

Authors would like to thank the National Institute of Technology Warangal (NITW) for providing the necessary research facilities.

\section{Authors' contributions}

AA analyzed and interpreted the modeling and simulation of the test system and controller. SN provided the idea and other technical guidance required for completion of the work. He also prepared the final draft of the manuscript. Both authors have read and approved the final manuscript.

\begin{abstract}
Authors' information
Anil Annamraju was born in Nellore, India. He received his B. Tech degree in Electrical and Electronics Engineering from Jawaharlal Nehru Technological University, Kakinada, India, in 2010 and M. Tech degree in Power systems from University of Calicut, India, in 2013. Currently, He is working as research scholar in the Electrical Engineering department, National Institute of Technology, Warangal, India. His research interests include Microgrid technologies, Power system stability, operation and Control with Intelligent Techniques. Srikanth Nandiraju received his B. Tech degree in Electrical and Electronics Engineering from Osmania University, Hyderabad, India, in 1988 and M. Tech degree in Power systems from REC, Warangal, India, in 1998. He received his Ph.D. degree from National Institute of Technology, Warangal, India, in 2006. Since 1989, he is working as faculty in various positions. Currently, he is working as associate professor in the Electrical Engineering department, National Institute of Technology, Warangal, India. He is a member of IEEE and Institute of Engineers (India). He published over 40 research papers in journals and conferences. His research interests include Power system stability, operation and control, application of intelligent techniques to Microgrid problems, Real time control of power system, HVDC and FACTS.
\end{abstract}

\section{Funding}

Not applicable.

\section{Availability of data and materials}

Data sharing not applicable to this article as no data were generated or analyzed during the study.

\section{Competing interests}

The authors declare that they have no competing interests.

Received: 5 February 2019 Accepted: 14 November 2019

Published online: 26 December 2019

\section{References}

1. Bevrani, H., Ghosh, A., \& Ledwich, G. (2010). Renewable energy sources and frequency regulation: Survey and new perspectives. IET Renewable Power Generation, 4, 438-457 https://doi.org/10.1049/iet-rpg.2009.0049.
2. Vachirasricirikul, S., \& Ngamroo, I. (2014). Robust LFC in a smart grid with wind power penetration by coordinated V2G control and frequency controller. IEEE Transactions on Smart Grid, 5, 371-380 https:/doi.org/10.1109/TSG.2013.2264921. 3. Kundur, P. (1996). Power system stability and control. Newyork: Mcgraw-Hill.

4. Liu, T., Hill, D. J., \& Zhang, C. (2016). Non-disruptive load-side control for frequency regulation in power systems. IEEE Transactions on Smart Grid, 7 2142-2153 https://doi.org/10.1109/TSG.2016.2538287.

5. Saxena, S., \& Hote, Y. V. (2018). PI controller based load frequency control approach for single-area power system having communication delay. IFAC-PapersOnLine, 51, 622-626 https:/doi.org/10.1016/j.jfacol.2018.06.165.

6. Lee KA, Yee H, Teo CY (1991) Self-tuning algorithm for automatic generation control in an interconnected power system. Electric Power Systems Research 20:157-165. https://doi.org/10.1016/0378-7796(91)90060-Z.

7. Singh, V. P., Kishor, N., \& Samuel, P. (2017). Improved load frequency control of power system using LMI based PID approach. Journal of the Franklin Institute, 354, 6805-6830 https://doi.org/10.1016/j.jfranklin.2017.08.031.

8. Daneshfar, F., \& Bevrani, H. (2010). Load-frequency control: A GA-based multi-agent reinforcement learning. IET Generation Transmission and Distribution, 4, 13-26 https://doi.org/10.1049/iet-gtd.2009.0168.

9. Ilias, H., Fikri, A., Zahari, M., et al. (2016). Optimisation of PID controller for load frequency controller in two-area power system using evolutionary particle swarm optimisation. Int J Elect Syst, 12(2), 315-324.

10. Kouba NEY, Menaa M, Hasni M, Boudour M (2015) Optimal control of frequency and voltage variations using PID controller based on particle swarm optimization. In: 2015 4th international conference on systems and control (ICSC). Pp 424-429.

11. Barisal, A. K. (2015). Comparative performance analysis of teaching learning based optimization for automatic load frequency control of multi-source power systems. International Journal of Electrical Power \& Energy Systems, 66, 67-77 https://doi.org/10.1016/j.ijepes.2014.10.019.

12. Shankar, G., \& Mukherjee, V. (2016). Load frequency control of an autonomous hybrid power system by quasi-oppositional harmony search algorithm. International Journal of Electrical Power \& Energy Systems, 78, 715734 https://doi.org/10.1016/j.jijepes.2015.11.091

13. Madasu, S. D. Kumar, M. L. S. S. \& Singh, A. K (2018). A flower pollination algorithm based automatic generation control of interconnected power system. Ain Shams Engineering Joumal, 9, 1215-1224 https:/doi.org/10.1016/jasej.2016.06.003.

14. Madasu, S. D., Kumar, M. L. S. S., \& Singh, A. K. (2017). Comparable investigation of backtracking search algorithm in automatic generation control for two area reheat interconnected thermal power system. Applied Soft Computing, 55, 197$210 \mathrm{https}$ //doi.org/10.1016/..asoc.2017.01.018.

15. Sivalingam, R., Chinnamuthu, S., \& Dash, S. S. (2017). A hybrid stochastic fractal search and local unimodal sampling based multistage PDF plus (1+PI) controller for automatic generation control of power systems. Journal of the Franklin Institute, 354, 4762-4783 https:/doi.org/10.1016/j.jfranklin.2017.05.038.

16. Guha, D., Roy, P. K., \& Banerjee, S. (2017). Study of differential search algorithm based automatic generation control of an interconnected thermal-thermal system with governor dead-band. Applied Soft Computing, 52, 160-175 https://doi.org/10.1016/j.asoc.2016.12.012.

17. Kouba NEY, Menaa M, Hasni M, Boudour M (2015) Optimal load frequency control based on artificial bee colony optimization applied to single, two and multi-area interconnected power systems. In: 2015 3rd international conference on control, engineering information technology (CEIT). Pp 1-6.

18. Abd-Elazim, S. M., \& Ali, E. S. (2016). Load frequency controller design via BAT algorithm for nonlinear interconnected power system. International Journal of Electrical Power \& Energy Systems, 77, 166-177 https://doi.org/10. 1016/j.ijepes.2015.11.029

19. Das, D. C., Roy, A. K., \& Sinha, N. (2012). GA based frequency controller for solar thermal-diesel-wind hybrid energy generation/energy storage system. International Journal of Electrical Power \& Energy Systems, 43, 262-279 https://doi.org/10.1016/j.ijepes.2012.05.025.

20. Magdy, G., Shabib, G., Elbaset, A. A., \& Mitani, Y. (2018). Optimized coordinated control of LFC and SMES to enhance frequency stability of a real multi-source power system considering high renewable energy penetration. Protection and Control of Modern Power Systems, 3, 39 https://doi.org/10.1186/s41601-018-0112-2.

21. Izadkhast, et al. (2015). An aggregate model of plug-in electric vehicles for primary frequnecy control. IEEE Transactions on Smart Grid, 30(3), 14751482. https://doi.org/10.1109/TPWRS.2015.2471091.

22. Kouba, N. E Y Menaa, M Hasni, M \& Boudour, M. (2016). LFC enhancement concerning large wind power integration using new optimised PID controller and RFBs. IET Generation Transmission and Distribution, 10, 4065-4077 https://doi.org/10.1049/iet-gtd.2016.0385. 
23. El-Fergany, A. A, \& E-Hameed, M. A. (2017). Efficient frequency controllers for autonomous two-area hybrid microgrid system using social-spider optimiser. IET Generation Transmission and Distribution, 11, 637-648 https//doi.org/10.1049/1et-gtd2016.0455.

24. Elsisi, M., Soliman, M., Aboelela, M. A. S., \& Mansour, W. (2017). Model predictive control of plug-in hybrid electric vehicles for frequency regulation in a smart grid. IET Generation Transmission and Distribution, 11, 3974-3983 https://doi.org/10.1049/iet-gtd.2016.2120.

25. Rao, R. V., \& Rai, D. P. (2017). Optimization of selected casting processes using Jaya algorithm. MaterialsToday: Proceedings, 4, 11056-11067 https:/ doi.org/10.1016/j.matpr.2017.08.067.

26. Abhishek, K, Kumar, V. R., Datta, S., \& Mahapatra, S. S. (2017). Application of JAYA algorithm for the optimization of machining performance characteristics during the turning of CFRP (epoxy) composites: Comparison with TLBO, GA, and ICA Engineering Computations, 33, 457-475 https:/doi.org/10.1007/s00366-016-0484-8.

27. Kumar, N., Hussain, I., Singh, B., \& Panigrahi, B. K. (2017). Rapid MPPT for uniformly and partial shaded PV system by using JayaDE algorithm in highly fluctuating atmospheric conditions. IEEE Transactions on Industrial Informatics, 13, 2406-2416 https://doi.org/10.1109/TII.2017.2700327.

\section{Submit your manuscript to a SpringerOpen ${ }^{\odot}$ journal and benefit from:}

- Convenient online submission

- Rigorous peer review

- Open access: articles freely available online

High visibility within the field

- Retaining the copyright to your article

Submit your next manuscript at $\boldsymbol{\nabla}$ springeropen.com 